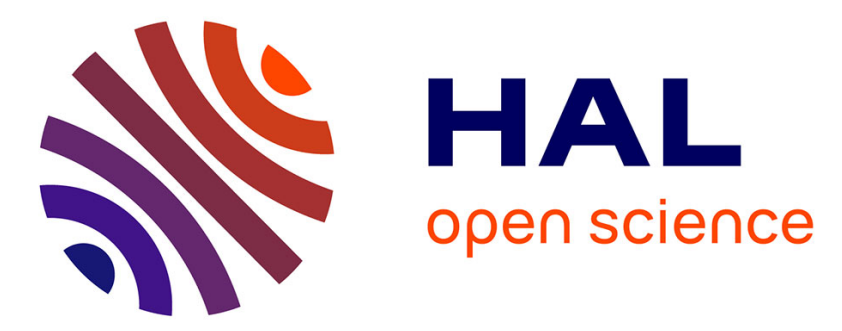

\title{
Trajectory planning of unmanned ground vehicles evolving on an uneven terrain with vertical dynamic consideration
}

Bachir Menkouz, Ahmed Bouzar Essaidi, Moussa Haddad, Taha Chettibi, Faïz Ben Amar

\section{To cite this version:}

Bachir Menkouz, Ahmed Bouzar Essaidi, Moussa Haddad, Taha Chettibi, Faïz Ben Amar. Trajectory planning of unmanned ground vehicles evolving on an uneven terrain with vertical dynamic consideration. Conference: 2015 4th International Conference on Electrical Engineering (ICEE), 2015, Alger, Algeria. 6-p., 10.1109/INTEE.2015.7416800 . hal-03178036

\section{HAL Id: hal-03178036 \\ https://hal.science/hal-03178036}

Submitted on 23 Mar 2021

HAL is a multi-disciplinary open access archive for the deposit and dissemination of scientific research documents, whether they are published or not. The documents may come from teaching and research institutions in France or abroad, or from public or private research centers.
L'archive ouverte pluridisciplinaire $\mathbf{H A L}$, est destinée au dépôt et à la diffusion de documents scientifiques de niveau recherche, publiés ou non, émanant des établissements d'enseignement et de recherche français ou étrangers, des laboratoires publics ou privés. 


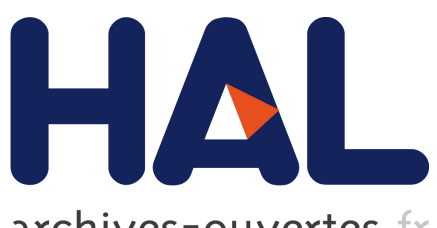

archives-ouvertes

\section{Trajectory planning of unmanned ground vehicles evolving on an uneven terrain with vertical dynamic consideration}

Bachir Menkouz, Ahmed Bouzar Essaidi, Moussa Haddad, Taha Chettibi, Faïz Ben Amar

\section{To cite this version:}

Bachir Menkouz, Ahmed Bouzar Essaidi, Moussa Haddad, Taha Chettibi, Faïz Ben Amar. Trajectory planning of unmanned ground vehicles evolving on an uneven terrain with vertical dynamic consideration. Conference: 2015 4th International Conference on Electrical Engineering (ICEE), 2015, Alger, Algeria. 6-p., 10.1109/INTEE.2015.7416800 . hal-03178036

\section{HAL Id: hal-03178036 \\ https://hal.archives-ouvertes.fr/hal-03178036}

Submitted on 23 Mar 2021

HAL is a multi-disciplinary open access archive for the deposit and dissemination of scientific research documents, whether they are published or not. The documents may come from teaching and research institutions in France or abroad, or from public or private research centers.
L'archive ouverte pluridisciplinaire HAL, est destinée au dépôt et à la diffusion de documents scientifiques de niveau recherche, publiés ou non, émanant des établissements d'enseignement et de recherche français ou étrangers, des laboratoires publics ou privés. 


\section{Trajectory planning of unmanned ground vehicles evolving on an uneven terrain with vertical dynamic consideration}

\author{
B. Menkouz, A.Bouzar Essaidi, M. Haddad and T. Chettibi \\ Laboratoire Mécanique des Structures, EMP \\ Bordj El Bahri, Algiers, Algeria \\ Email: b.menkouz@gmail.com
}

\author{
Faïz Ben Amar \\ Université Pierre et Marie Curie \\ Institut des Systèmes Intélligents et de Robotique \\ Paris, France \\ Email:amar@isir.upmc.fr
}

\begin{abstract}
In this paper, we treat the problem of trajectory planning of an unmanned ground vehicle evolving on an uneven terrain. In such environment, the role of the suspension system cannot be neglected and a vehicle vertical model has to be taken into account. In the present work, we present three reduced models with different level of complexity. These models make possible to handle the constraints inherent to stability, embedded equipment safety and suspension mechanical integrity.An optimization problem is also formulated in order to define the optimal speed profile for a safety behaviour of the mobile robot.
\end{abstract}

Keywords-Trajectory planning, UGV, optimal velocity profile, vehicle dynamics, suspension system, uneven terrain.

\section{INTRODUCTION}

Nowadays, Unmanned Ground Vehicles $(U G V)$ are deployed in different fields to accomplish tasks such as military transportation, sensible site inspection and nuclear zone intervention. $U G V s$ are therefore called to evolve within hostile environments where trajectory planning is a key function when preparing movement task in order to increase robot chances to attempt its goal in best circumstances. A lot of previous works treated mobile robot trajectory planning. Works such as [6] and [8] took into account robot motion limitation by adding nonholonomic equations in their models. Such works considered the fact that $U G V s$ were moving on laboratory surfaces where road was supposed to be plane. For more complex applications of $U G V s$, environment is composed of 3D and/or uneven surfaces. In such cases, works like [1] and [10] developed strategies where optimal motion was calculated using a $U G V$ dynamic model-based algorithm. In other works, kinematic and dynamic models were coupled with $A^{*}$ and $R R T$ algorithms [3], [4], [7], [9], [11].

In these works, the robot is considered as a rigid body. However, riding on an uneven or rough surfaces will cause instability risks and eventually integrity problems, that are directly related to suspensions parameters. Therefore, results obtained with trajectory planner that do not consider such a system could be fatal in some situations. Actually there are works such as [5] and [2] that considered suspension system, but they dealt with another type of robot like wheeled-legged one.

In this work, we propose a particular general vertical dynamic model that can be used either within quarter-car, bicycle and full models. We propose also a strategy based on two steps to calculate the optimal velocity profile along a longitudinal uneven path with taking into account the robot vertical behaviour. Finally we present an application of this strategy on an uneven terrain.

\section{VEHICLE VERTICAL DYNAMIC MODEL}

The suspension system role is not only to isolate embedded equipments from external perturbations, but also to maintain contact between tyres and ground to assure permanent control and therefore to operate safely. In this section, we present three reduced dynamics models: the quarter-car, the bicycle and the four (04) wheeled. All of them are based on sprung and unsprung masses concept. Selecting a model among these three models depends on the complexity level of the vehicle vertical dynamic model used within an eventual study where the effect of the suspension system of the considered vehicle cannot be neglected. However, a general vertical dynamic model form that allows passing from a model to another with minimum modification will be presented.

\section{A. Quarter-car model}

This model is used when dynamic analysis is focussed on bounce motion. The vehicle is supposed composed of a sprung mass (chassis) $m_{c}$ linked to an unsprung mass (wheel) $m_{w}$ via a suspension system (Figure 1). The latter is composed of a spring with stiffness $k$ and a damper with coefficient $c$. The tyre is supposed to be elastic with stiffness $k_{w}$. Both masses are localized by their vertical positions $z_{c}$ and $z_{w}$ receptively. The ground elevation is noted $z_{s} . u$ is the force applied by an eventual active system. The dynamic of system is described using the following differential equation:

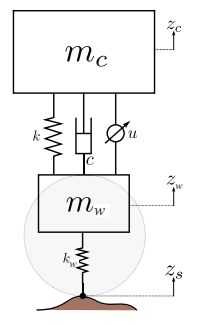

Fig. 1: Quarter-car model. 
$\left\{\begin{array}{l}m_{c} \ddot{z}_{c}+c\left(\dot{z}_{c}-\dot{z}_{w}\right)+k\left(z_{c}-z_{w}\right)=u \\ m_{w} \ddot{z}_{w}+k_{w}\left(z_{w}-z_{s}\right)-c\left(\dot{z}_{c}-\dot{z}_{w}\right)-k\left(z_{c}-z_{w}\right)=-u\end{array}\right.$

Using the following variables replacement: $x_{1}=z_{c}-z_{w}$, $x_{2}=\dot{z}_{c}, x_{3}=z_{w}-z_{s}$ and $x_{4}=\dot{z}_{w}$.

We obtain

$$
\left\{\begin{array}{l}
m_{c} \dot{x}_{2}+c\left(x_{2}-x_{4}\right)+k x_{1}=u \\
m_{w} \dot{x}_{4}+k_{w} x_{3}-c\left(x_{2}-x_{4}\right)-k x_{1}=-u
\end{array}\right.
$$

With

- $x_{1}$ : suspension deformation;

- $x_{2}$ : chassis vertical velocity;

- $\quad x_{3}$ : tyre deflection;

- $x_{4}$ : tyre vertical velocity.

By deriving the first and the third equations of system (??) and adding the result to system (2) we get:

$$
\left\{\begin{array}{l}
\dot{x}_{1}-\dot{z}_{c}+\dot{z}_{w}=0 \\
m_{c} \dot{x}_{2}+c\left(x_{2}-x_{4}\right)+k x_{1}-u=0 \\
\dot{x}_{3}-\dot{z}_{w}+\dot{z}_{s}=0 \\
m_{w} \dot{x}_{4}+k_{w} x_{3}-c\left(x_{2}-x_{4}\right)-k x_{1}+u=0
\end{array}\right.
$$

This system is rewritten in the following form:

$$
\begin{aligned}
& \begin{array}{l}
\underbrace{\left(\begin{array}{cccc}
1 & 0 & 0 & 0 \\
0 & m_{c} & 0 & 0 \\
0 & 0 & 1 & 0 \\
0 & 0 & 0 & m_{w}
\end{array}\right)}_{M} \underbrace{\left(\begin{array}{cccc}
0 & -1 & 0 & 1 \\
k & c & 0 & -c \\
0 & 0 & 0 & -1 \\
-k & -c & k_{w} & c
\end{array}\right)}_{K} \underbrace{\left(\begin{array}{l}
\dot{x}_{1} \\
\dot{x}_{2} \\
\dot{x}_{3} \\
\dot{x}_{4}
\end{array}\right)}_{x}+ \\
\underbrace{\left(\begin{array}{l}
x_{1} \\
x_{2} \\
x_{3} \\
x_{4}
\end{array}\right)}_{\dot{x}}+
\end{array} \\
& \underbrace{\left(\begin{array}{l}
0 \\
0 \\
1 \\
0
\end{array}\right) \dot{z}_{s}+\left(\begin{array}{l}
0 \\
-1 \\
0 \\
1
\end{array}\right)}_{D} u=\left(\begin{array}{l}
0 \\
0 \\
0 \\
0
\end{array}\right)
\end{aligned}
$$

In this model $\dot{z}_{s}$ and eventually $u$ are the input of the model.

\section{B. Bicycle model}

In addition to bounce movement, this model permits to study the robot pitch angle $\theta$ (the corresponding inertia moment is $I_{\theta}$ ). In this case, unsprung mass is composed of two wheels, front and right. Both of wheels are linked to the chassis by a suspension system with the characteristics $k_{f}, c_{f}, k_{r}$ and $c_{r}$ ( $f$ for front and $r$ for rear). Their longitudinal distances to the centre of mass are respectively $l_{f}$ and $l_{r}$ (figure 2 ).

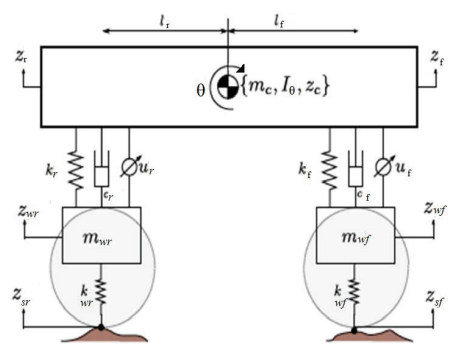

Fig. 2: Bicycle model.

The dynamics of the robot is described by the following set of ODEs:

$$
\begin{aligned}
& \left\{\begin{array}{c}
m_{c} \ddot{z}_{c}+c_{f}\left(\dot{z}_{f}-\dot{z}_{w f}\right)+k_{f}\left(z_{f}-z_{w f}\right)+ \\
I_{\theta} \ddot{\theta}-l_{f} c_{f}\left(\dot{z}_{f}-\dot{z}_{w f}\right)-l_{f} k_{f}\left(z_{f}-z_{w f}\right)+ \\
m_{w f} \ddot{z}_{w f}+k_{w f}\left(z_{w f}-z_{s f}\right)- \\
m_{w r} \ddot{z}_{w r}+k_{w r}\left(z_{w r}-z_{s r}\right)-
\end{array}\right. \\
& \left\{\begin{array}{c}
c_{r}\left(\dot{z}_{r}-\dot{z}_{w r}\right)+k_{r}\left(z_{r}-z_{w r}\right)=u_{f}+u_{r} \\
l_{r} c_{r}\left(\dot{z}_{r}-\dot{z}_{w r}\right)+l_{r} k_{r}\left(z_{r}-z_{w r}\right)=-l_{f} u_{f}+l_{r} u_{r} \\
c_{f}\left(\dot{z}_{f}-\dot{z}_{w f}\right)-k_{f}\left(z_{f}-z_{w f}\right)=-u_{f} \\
c_{r}\left(\dot{z}_{r}-\dot{z}_{w r}\right)-k_{r}\left(z_{r}-z_{w r}\right)=-u_{r}
\end{array}\right.
\end{aligned}
$$

Performing the variables replacements given in (6), we obtain the equations of motion with compact form (7).

$$
\left\{\begin{array}{l}
x_{1 j}=z_{j}-z_{w j} \\
x_{2 j}=\dot{z}_{j} \\
x_{3 j}=z_{w j}-z_{s j} \\
x_{4 j}=\dot{z}_{w j}
\end{array}\right.
$$

With $j=\{f, r\}$. 


$$
\begin{aligned}
& \underbrace{\left(\begin{array}{cccc}
I & 0 & 0 & \overbrace{0}^{2 \times 2} \\
0 & M^{\prime}{ }_{c} & 0 & 0 \\
0 & 0 & I & 0 \\
0 & 0 & 0 & M_{w}
\end{array}\right)}_{M}\left(\begin{array}{c}
\dot{X}_{1} \\
\dot{X}_{2} \\
\dot{X}_{3} \\
\dot{X}_{4}
\end{array}\right)+ \\
& \underbrace{\left(\begin{array}{cccc}
0 & -I & 0 & I \\
K_{c} & C_{c} & 0 & -C_{c} \\
0 & 0 & 0 & -I \\
-K_{c} & -C_{c} & K_{w} & C_{c}
\end{array}\right)}_{K} \underbrace{\left(\begin{array}{c}
X_{1} \\
X_{2} \\
X_{3} \\
X_{4}
\end{array}\right)}_{X}+ \\
& \underbrace{\left(\begin{array}{l}
0 \\
0 \\
I \\
0
\end{array}\right) \dot{Z}_{s}+\left(\begin{array}{l}
0 \\
-I \\
0 \\
I
\end{array}\right)}_{D} U=\underbrace{\left(\begin{array}{l}
0 \\
0 \\
0 \\
0
\end{array}\right)^{X}}_{8 \times 1}
\end{aligned}
$$

Where:

- $\quad I$ is $(2 \times 2)$ identity matrix; $M_{c}^{\prime}=G^{t} M_{c} G$;

- $M_{c}=\left(\begin{array}{cc}m_{c} & 0 \\ 0 & I_{\theta}\end{array}\right) ; G=\left(\begin{array}{cc}1 & 1 \\ -l_{f} & l_{r}\end{array}\right)$;

- $K_{c}=\left(\begin{array}{cc}k_{f} & 0 \\ 0 & k_{r}\end{array}\right) ; C_{c}=\left(\begin{array}{cc}c_{f} & 0 \\ 0 & c_{r}\end{array}\right) ;$

- $M_{w}=\left(\begin{array}{cc}m_{w} & 0 \\ 0 & m_{w}\end{array}\right) ; K_{w}=\left(\begin{array}{cc}k_{w} & 0 \\ 0 & k_{w}\end{array}\right)$;

- $X_{i}=\left(x_{i f}, x_{i r}\right)^{t}$ and $i=\{1,2,3,4\} ; Z s=$ $\left(z_{s f}, z_{s r}\right)^{t}$

- $U=\left(u_{s f}, u_{s r}\right)^{t}$.

\section{Full model}

This model is used if one is interested to study the bounce, the pitch and the roll movements of the robot. The model is described in the figure 3 where $\varphi$ and $I_{\varphi}$ are respectively chassis roll angle and inertia moment. $d$ is the half of track.

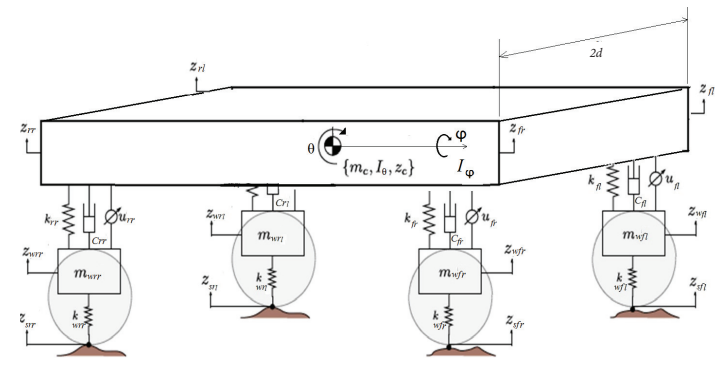

Fig. 3: Full model.

For this case, one can easily prove that the state motion system is similar to those presented by equations (4) and (7). The general form is presented in equation (8).

$$
\begin{aligned}
& \underbrace{\left(\begin{array}{cccc}
\overbrace{I}^{n \times n} & 0 & 0 & \overbrace{0}^{n \times n} \\
0 & M^{\prime}{ }_{c} & 0 & 0 \\
0 & 0 & I & 0 \\
0 & 0 & 0 & M_{w}
\end{array}\right)}_{M_{(4 n \times 4 n)}}\left(\begin{array}{c}
\dot{X}_{1} \\
\dot{X}_{2} \\
\dot{X}_{3} \\
\dot{X}_{4}
\end{array}\right) \\
& +\underbrace{\left(\begin{array}{cccc}
0 & -I & 0 & I \\
K_{c} & C_{c} & 0 & -C_{c} \\
0 & 0 & 0 & -I \\
-K_{c} & -C_{c} & K_{w} & C_{c}
\end{array}\right)}_{K_{(4 n \times 4 n)}} \underbrace{\left(\begin{array}{c}
\overbrace{X_{1}}^{n \times 1} \\
X_{2} \\
X_{3} \\
X_{4}
\end{array}\right)}_{X_{(4 n \times 1)}} \\
& +\underbrace{\left(\begin{array}{l}
0 \\
0 \\
I \\
0
\end{array}\right) \dot{Z}_{s(4 n \times 1)}+\left(\begin{array}{l}
0 \\
-I \\
0 \\
I
\end{array}\right) U_{(4 n \times 1)}}_{D}=\underbrace{\left(\begin{array}{l}
0 \\
0 \\
0 \\
0
\end{array}\right)}_{16 \times 1}
\end{aligned}
$$

This equation has the following form :

$$
\dot{X}=A X+B
$$

With $A=M^{-1} K$ and $B=M^{-1} D$.

Details of this form are listed in table I, where $n$ indicates the number of wheels considered in the model.

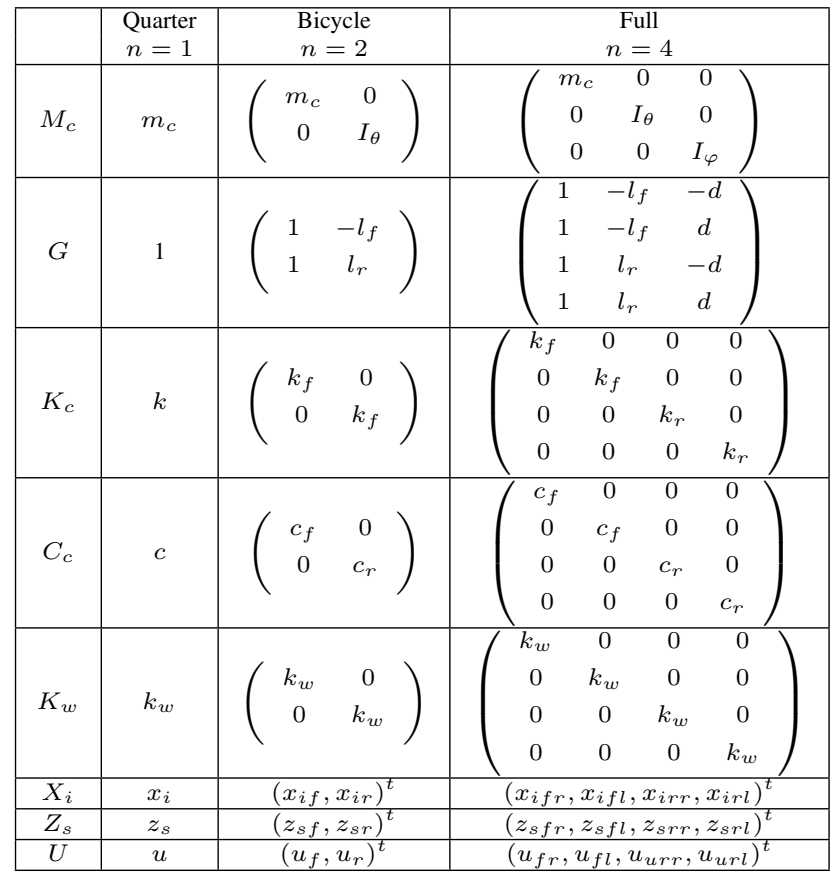

TABLE I: Movement equations global form details.

This general form allows to anyone to switch from a model to another with minimum modifications. The choice of a model 
depends on the application. In the following section, a method to find an optimal velocity profile along a longitudinal path is proposed. We will show how to take into account the vehicle vertical dynamic using the quarter-car model.

\section{TRAJECTORY PLANNING TAKING INTO ACCOUNT VERTICAL DYNAMICS}

If an $U G V$ has to move on an uneven path with important velocity, embedded equipment safety and stability must be taken into account. These two performance indices are assured by a suspension system supposed composed of springs and dampers as seen above. However, as any mechanical system, suspension has stops that can be damaged because of excessive deformation. Wheel axle also can be broken because of an important vertical force. For this reason, robot mechanical integrity must be preserved at first by planning movement that prevent stops to be attempt during riding and by limiting force applied on the axle and therefore, suspension will perform safely.

In the following section we will propose a method to determine the optimal velocity profile along a longitudinal path that minimizes an objective function that consider the execution time, the comfort, the stability and the consumed energy. This problem is constrained by the robot mechanical integrity and also accelerating and breaking limits.

\section{A. Planning strategy}

Let be a ground profile defined by the the road elevation $z_{s}$ along a longitudinal path. The aim of the developed strategy is to find an optimal velocity $v_{o p t}$ along this path (figure 4).

The planning strategy is based on two steps.

- $\quad$ Step 1: obtain an optimal velocity profile that preserve the suspension mechanical system;

- $\quad$ Step 2: deduce from the first profile a new one that takes into account accelerating and breaking limits in addition to comfort and stability indices;

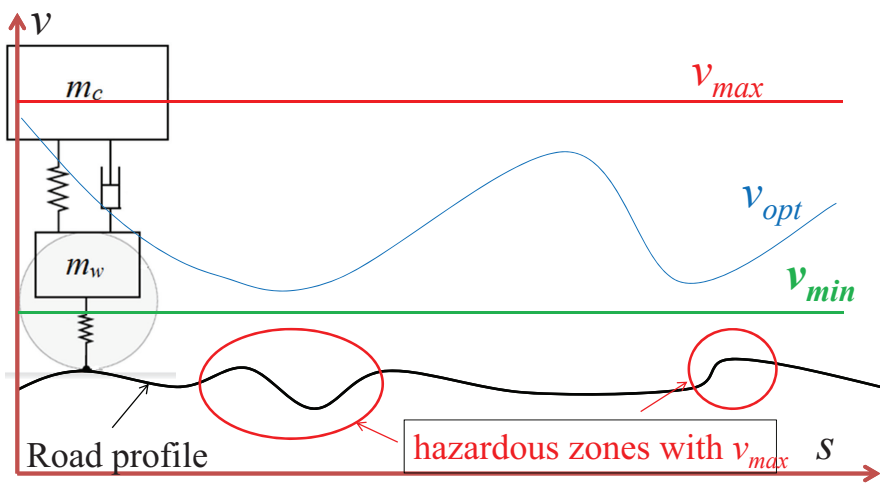

Fig. 4: Optimal velocity profile concept.

1) Step 1: Preserving the robot mechanical structure: in this work, preserving the robot mechanical structure is taken into account by limiting the vertical force applied on the wheel axle $F_{a}$ and the contact force $F_{c}$ between ground and tyre. The optimization problem can formulated as follows: $\min \left(f_{o b j}=\right.$
$T)$. Where $f_{o b j}$ is the objective function and $T$ is travel time. The considered constraints are:

$$
\left\{\begin{array}{l}
\max \left(F_{a}\right)-F_{a \max }<0 \\
-\left(\min \left(F_{a}\right)+F_{a \min }\right)<0 \\
\max \left(F_{c}\right)-F_{c \max }<0 \\
-\min \left(F_{c}\right)<0 \\
v_{\min } \leq v_{o p t 1} \leq v_{\max }
\end{array}\right.
$$

Where $F_{a m a x}$ and $F_{a m i n}$ are the maximal and minimal authorized forces that can support the axle; and $F_{c \max }$ is the maximal force authorized that can support the tyre.

Velocity profile is obtained by interpolating $N_{p}$ nodes $p_{i}\left(s_{i}, v_{i}\right), i=\left\{1,2, \ldots, N_{p}\right\}$ (figure 5). The optimization process will search for best location of the nodes such as $f_{o b j}$ is minimized and constraints are repected.

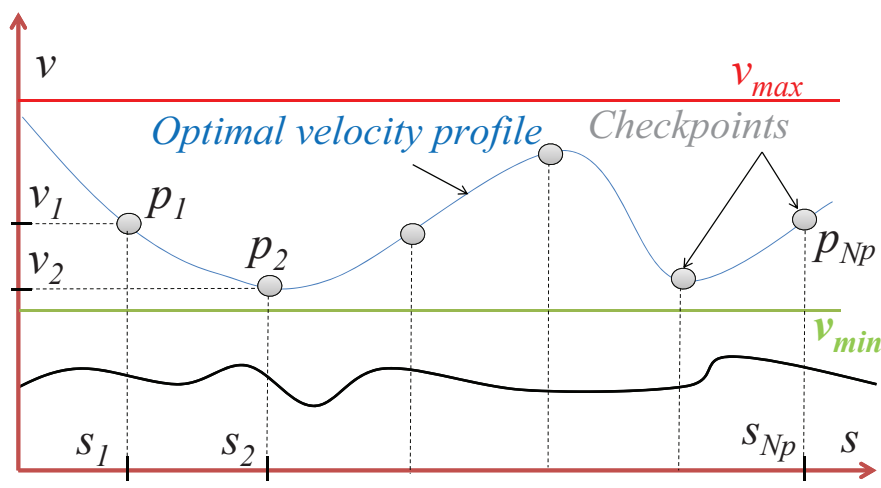

Fig. 5: Velocity profile obtained from optimization parameters.

In order to illustrate this method, we will analyse the following two scenarios.

Scenario 1: the robot is moving along an uneven path with a velocity profile that corresponds to a bang-bang movement (figure 6). The time of task execution is $T=1.5 \mathrm{~s}$. However the figure shows that forces applied on axle and tyre exceed authorized values.
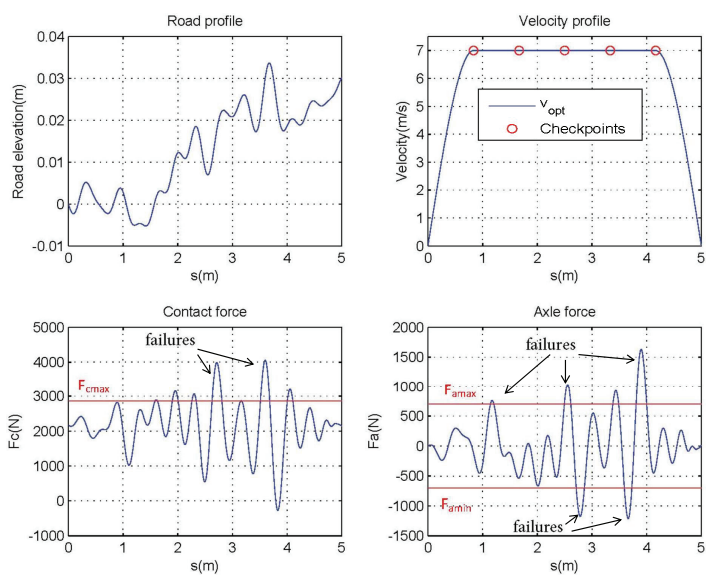

Fig. 6: Scenario 1:non optimized velocity profile. 
Scenario 2: the profile seen in figure 6, will be optimized taking account of preserving the mechanical structure. The obtained profile $v_{o p t 1}$ is within figure 7 . Note that axle and tyre forces are within authorized range but execution time $\mathrm{T}$ increased from $1.5 \mathrm{~s}$ to $2.6 \mathrm{~s}$.
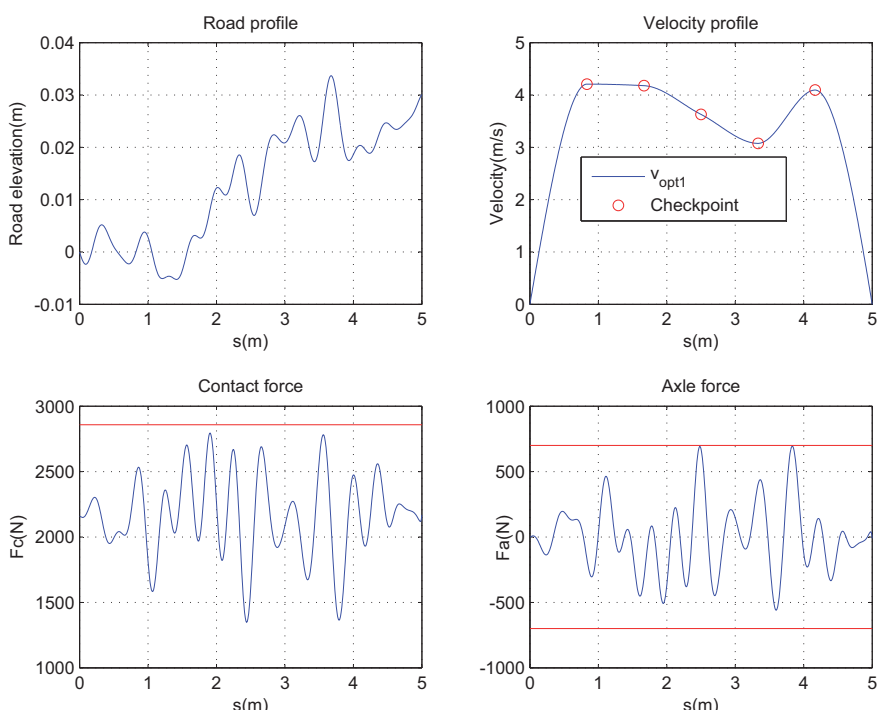

Fig. 7: Velocity profile optimization with preserving the robot mechanical structure.

2) Step 2: Taking into account energy, comfort and stability performance with traction and breaking limits: in this step, $v_{\max }$ that appears in constraints defined in system (10) will be substituted by $v_{o p t 1}$, optimized profile obtained in the first step. In addition the new objective function is:

$$
f_{o b j}=\lambda_{1} f_{o b j 1}+\lambda_{2} f_{o b j 2}+\lambda_{3} f_{o b j 3}+\lambda_{4} f_{o b j 4}
$$

Where:

$$
\begin{gathered}
f_{o b j 1}=\frac{1}{v_{\max }} \sum\left(v_{o p t 1}-v_{o p t 2}\right) \\
f_{o b j 2}=\frac{1}{E_{\max }} E \\
f_{o b j 3}=-\frac{1}{g} \sqrt{\operatorname{var}\left(a_{c}\right)} \\
f_{o b j 4}=-\frac{1}{g} \sqrt{\operatorname{var}\left(a_{w}\right)}
\end{gathered}
$$

With:

- $v_{\max }$ : robot maximal velocity;

- $E$ : energy consumed along the path;

- $E_{\max }$ : maximal energy that can be consumed with maximal acceleration along the path;
- $a_{c}$ : chassis vertical acceleration (used to quantify the comfort);

- $a_{w}$ : wheel vertical acceleration (used to quantify the stability);

- $\operatorname{var}(x): x$ variance;

- $\lambda_{i}$ : weight attributed to $f_{o b j_{i}}$.

New considered constraints are:

$$
\left\{\begin{array}{l}
-F_{x \max } \leq F_{x} \leq F_{x \max } \\
v_{\min } \leq v_{\text {opt } 2} \leq v_{\text {opt } 1}
\end{array}\right.
$$

Where $F_{x}$ is the longitudinal force and $F_{x \max }$ is the maximal force that can be developed. It is given by :

$$
F_{x \max }=\mu F_{c}
$$

$\mu$ is the adherence coefficient.

\section{APPLICATION ON AN UNEVEN TERRAIN}

In figure 8 , is presented an uneven terrain elevation map. The robot has to move from Start point to the Goal point. A shortest path (the blue line) is calculated using an algorithm that penalizes the zones where the variance of elevations is high. Details about this algorithm are not the scope of this paper. Then, a ground profile is extracted and an optimal velocity profile is calculated as seen in the previous section. The obtained result is presented in figure 9 .

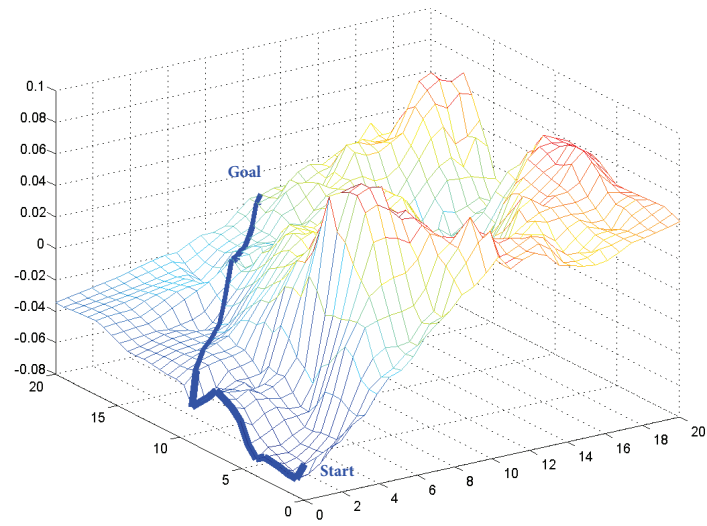

Fig. 8: An uneven terrain elevation map.

\section{CONCLUSION}

In this paper, we have proposed a method that takes into account the vertical dynamics when planning the trajectory of an $U G V$. The adopted strategy is composed of two steps. The first one determines an optimal velocity profile while considering the constraint of preserving the mechanical structure of the suspension system. In the second step, the latter profile is used as maximal when looking for a new one that considers energy, comfort and stability performances indices in one hand, and traction and breaking limits in the other hand. 

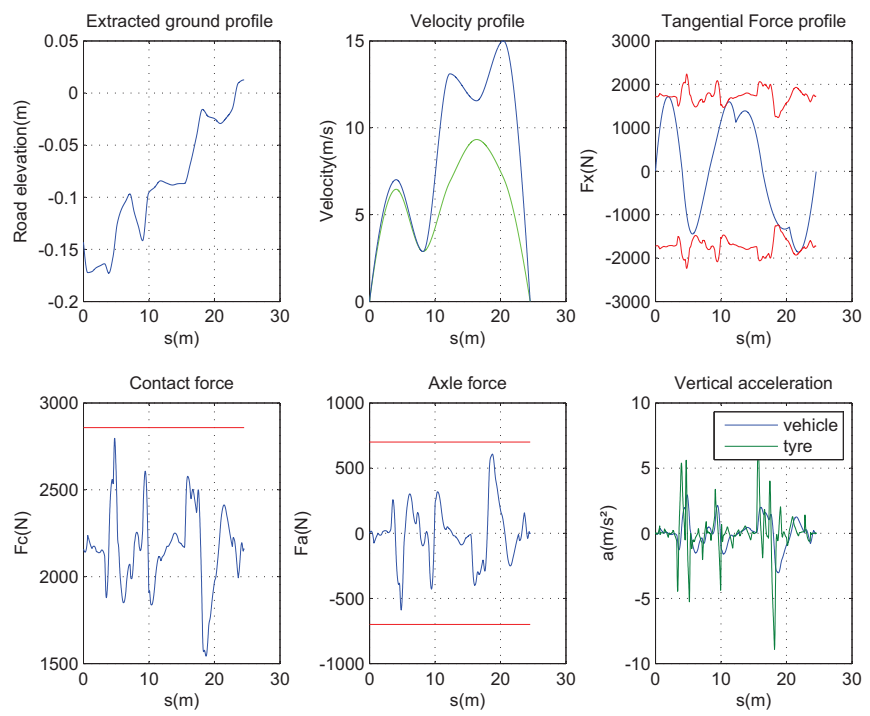

Fig. 9: An uneven terrain elevation map.

An application has been performed on an uneven terrain where a shortest path was calculated before applying the proposed method.

Obtained results are satisfactory and their experimental validation constitute the aim of a future work.

\section{REFERENCES}

[1] M. Cherif, C. Laugier, C. Milesi-Bellier, and B. Faverjon. Planning the motions of an all-terrain vehicle by using geometric and physical models. In Robotics and Automation, 1994. Proceedings., 1994 IEEE International Conference on, pages 2050-2056. IEEE, 1994.

[2] C. Grand, F. Benamar, and F. Plumet. Motion kinematics analysis of wheeled-legged rover over 3D surface with posture adaptation. Mechanism and Machine Theory, 45(3):477-495, 2010.

[3] J. hwan Jeon, R. V. Cowlagi, S. C. Peters, S. Karaman, E. Frazzoli, P. Tsiotras, and K. Iagnemma. Optimal motion planning with the halfcar dynamical model for autonomous high-speed driving. In American Control Conference (ACC), 2013, pages 188-193. IEEE, 2013.

[4] K. Iagnemma, F. Genot, and S. Dubowsky. Rapid physics-based rough-terrain rover planning with sensor and control uncertainty. In Robotics and Automation, 1999. Proceedings. 1999 IEEE International Conference on, volume 3, pages 2286-2291. IEEE, 1999.

[5] K. D. Iagnemma, A. Rzepniewski, S. Dubowsky, P. Pirjanian, T. L. Huntsberger, and P. S. Schenker. Mobile robot kinematic reconfigurability for rough terrain. In Intelligent Systems and Smart Manufacturing, pages 413-420. International Society for Optics and Photonics, 2000.

[6] P. Jacobs and J. Canny. Planning smooth paths for mobile robots. In Nonholonomic Motion Planning, pages 271-342. Springer, 1993.

[7] G. Kewlani, G. Ishigami, and K. Iagnemma. Stochastic mobility-based path planning in uncertain environments. In Intelligent Robots and Systems, 2009. IROS 2009. IEEE/RSJ International Conference on, pages 1183-1189. IEEE, 2009.

[8] J.-P. Laumond. Finding collision-free smooth trajectories for a nonholonomic mobile robot. In IJCAI, pages 1120-1123, 1987.

[9] R. Pepy, A. Lambert, and H. Mounier. Path planning using a dynamic vehicle model. In Information and Communication Technologies, 2006. ICTTA'06. 2nd, volume 1, pages 781-786. IEEE, 2006.

[10] Z. Shiller and Y.-R. Gwo. Dynamic motion planning of autonomous vehicles. Robotics and Automation, IEEE Transactions on, 7(2):241249, 1991.
[11] Z. Shiller, S. Sharma, I. Stern, and A. Stern. Online obstacle avoidance at high speeds. The International Journal of Robotics Research, 32(910):1030-1047, 2013. 